\title{
Response to duloxetine in patients with knee pain due to osteoarthritis: an exploratory post hoc analysis of a Japanese Phase III randomized study
}

This article was published in the following Dove Press journal: Journal of Pain Research

\author{
Naohiro Itoh' \\ Toshinaga Tsuji' \\ Mitsuhiro Ishida ${ }^{2}$ \\ Toshimitsu Ochiai ${ }^{3}$ \\ Shinichi Konno ${ }^{4}$ \\ Yuji Uchio ${ }^{5}$ \\ 'Medical Affairs Department, Shionogi \\ \& Co. Ltd, Osaka, Japan; ${ }^{2}$ Clinical \\ Development Department, Shionogi \\ \& Co. Ltd, Osaka, Japan; ${ }^{3}$ Biostatistics \\ Center, Shionogi \& Co. Ltd, Osaka, \\ Japan; ${ }^{4}$ Department of Orthopaedic \\ Surgery, Fukushima Medical University, \\ Fukushima, Japan; ${ }^{5}$ Department \\ of Orthopaedic Surgery, Shimane \\ University School of Medicine, \\ Shimane, Japan
}

Correspondence: Toshinaga Tsuji Medical Affairs Department, Shionogi \& Co. Ltd, I 2F, Hankyu Terminal Bldg, I-4-I, Shibata, Kita-ku, Osaka 530-00I2, Japan

$\mathrm{Tel}+81664855210$

Fax +8I 663755780

Email toshinaga.tsuji@shionogi.co.jp
Purpose: To assess whether patients with knee osteoarthritis pain who have early pain reduction or treatment-related adverse events of special interest (TR-AESIs; constipation, decreased appetite, malaise, nausea, somnolence, thirst) with duloxetine treatment are more likely to have later improvements in pain and quality of life (QOL) relative to placebo than patients without these early indicators.

Patients and methods: This was a post hoc analysis of 14-week randomized trial of Japanese patients with knee osteoarthritis pain (Brief Pain Inventory [BPI]-Severity average pain score $\geq 4$ ) receiving duloxetine $60 \mathrm{mg} /$ day ( $\mathrm{n}=177$ analyzed) or placebo $(\mathrm{n}=176)$. Primary trial outcome was change from baseline in BPI-Severity average pain at Week 14. Subgroups included early pain reduction ( $\geq 30 \%, 10 \%-30 \%$, or $<10 \%$ decrease in BPI-Severity average pain at Week 4 ) and early TR-AESIs (with/without TR-AESIs by Week 2). Measures included changes from baseline in BPI-Severity average pain, QOL (BPI-Interference, Western Ontario and McMaster Universities Osteoarthritis Index), Patient Global Impression of Improvement (PGI-I), and response rate (proportion achieving $\geq 30 \%$ or $\geq 50 \%$ pain reduction at Week 14 ).

Results: The $\geq 30 \%$ early pain reduction subgroup ( $n=93$ ) had significantly greater improvements in pain, QOL, and PGI-I and higher $\geq 30 \%$ and $\geq 50 \%$ response rates than placebo; the $10 \%-30 \%(n=45)$ and the $<10 \%(n=33)$ pain reduction subgroups did not show the same (except 10\%-30\% group: PGI-I at Week 10 and some QOL at Weeks 10 and/or 14). Both TR-AESI subgroups (with, $\mathrm{n}=52$; without, $\mathrm{n}=125$ ) had significantly greater improvements in pain, PGI-I, and most QOL measures and higher response rates than placebo.

Conclusion: Early efficacy responses to duloxetine treatment, but not early TR-AESIs, may predict later pain reduction and QOL improvements in Japanese patients with knee osteoarthritis pain.

ClinicalTrials. gov: NCT02248480.

Keywords: Brief Pain Inventory, responder analysis, WOMAC

\section{Introduction}

Knee osteoarthritis (OA) is a common form of OA that is often associated with pain and disability. ${ }^{1}$ Studies carried out in the US show that $12 \%-16 \%$ of older adults have OA knee pain. ${ }^{2}$ Knee pain due to OA may be more common in Japan, according to the results of a population-based cohort study in which $26 \%$ of adults aged 60 years or older had radiographic knee OA with pain. ${ }^{3} \mathrm{OA}$ can have a significant negative impact on quality of life (QOL), including activities of daily living, and is associated with an economic burden. ${ }^{4-6}$ Therefore, relief of OA knee pain is of great importance to patients. 
Duloxetine is a serotonin and noradrenaline reuptake inhibitor that is widely approved as an analgesic. In Japan, duloxetine is approved for the treatment of diabetic neuropathic pain, chronic low back pain (CLBP), fibromyalgia, and OA-related pain. ${ }^{7-9}$ Recently reported findings of a Phase III, randomized, placebo-controlled trial ${ }^{8}$ demonstrated that duloxetine was superior to placebo for reducing knee pain in Japanese patients with knee OA, with no unexpected safety findings. Importantly, improvements in QOL were also greater with duloxetine than placebo. As with other pain medications, although duloxetine can effectively relieve pain, not all patients respond equally to treatment. In patients with OA, the number needed to treat (ie, the number of patients that need to be treated in order for one patient to benefit) for duloxetine ranges from 5.3 to 8.6, depending on the targeted level of pain intensity reduction. ${ }^{10}$ Findings from a recent post hoc analysis of Japanese patients with CLBP treated with duloxetine indicated that early pain reduction ( $\geq 30 \%$ reduction at Week 4 ) or early occurrence (by 2 weeks) of treatment-related adverse events of special interest (TR-AESIs; nausea, somnolence, and constipation) were good indicators of later, clinically meaningful pain reduction. ${ }^{11}$ Being able to identify which patients with OA knee pain are most likely to benefit from duloxetine would be of substantial benefit from both the clinician and patient perspective.

The objective of this post hoc analysis of a Japanese randomized, placebo-controlled trial ${ }^{8}$ was to assess whether patients with OA knee pain who experience early pain reduction or early TR-AESIs (constipation, decreased appetite, malaise, nausea, somnolence, and thirst) with duloxetine are more likely to have later improvements in pain and QOL relative to placebo than patients without these early indicators.

\section{Patients and methods}

\section{Study design}

This was a post hoc analysis of a multicenter, randomized, placebo-controlled, double-blind trial carried out at 47 sites in Japan from October 2014 to June $2015 .{ }^{8}$ Further details regarding the study design can be found in the primary manuscript. ${ }^{8}$ The trial was registered at ClinicalTrials.gov (NCT02248480), approved by the Institutional Review Board of each study site (see Supplementary material), and carried out in accordance with Good Clinical Practice, the ethical standards of the responsible committee on human experimentation, and the Declaration of Helsinki. All patients provided written informed consent.

\section{Study population}

The trial included male or female outpatients aged 40-79 years who met the American College of Rheumatology criteria $^{12}$ for idiopathic knee OA, had experienced pain for $\geq 14$ days/month during the 3-month period before the trial, and had a Brief Pain Inventory (BPI)-Severity average pain score of $\geq 4$. Patients were excluded if they had inflammatory arthritis or autoimmune diseases (except Hashimoto's disease and type 1 diabetes mellitus), invasive treatment in either knee within 1 month before the trial, arthroscopic surgery of the affected joint within 1 year before the trial or a history of joint replacement or osteotomy, end-stage OA or were scheduled to undergo surgery of the affected joint during the trial, or major depressive disorders or suicidal tendencies.

For this post hoc analysis, patients were divided into subgroups depending on the extent of pain reduction at Week $4(\geq 30 \%, 10 \%-30 \%$, or $<10 \%$ pain reduction, based on BPISeverity average pain score) and the presence or absence of TR-AESIs (constipation, decreased appetite, malaise, nausea, somnolence, and thirst) within the first 2 weeks of treatment. The pain reduction subgroups were chosen based on standard cut-offs for moderate $(>30 \%)$ and minimal $(>10 \%)$ clinically significant improvement. ${ }^{13}$ The TR-AESIs were chosen because they occurred in $\geq 5 \%$ of patients in the duloxetine group and were significantly more common with duloxetine than with placebo. ${ }^{8}$

\section{Treatment protocol}

Patients were randomized $(1: 1)$ to receive duloxetine $(20$ $\mathrm{mg} /$ day for 1 week, followed by $40 \mathrm{mg} /$ day for 1 week and then $60 \mathrm{mg}$ /day for 12 weeks) or placebo for 14 weeks. All patients underwent tapering after the completion of treatment or following discontinuation after 2 weeks of treatment.

\section{Outcome measures}

The primary objective of the trial ${ }^{8}$ was to assess the change from baseline to Week 14 in BPI-Severity average pain ${ }^{14}$ for duloxetine compared with placebo. In this post hoc analysis, we evaluated the following measures for each subgroup of duloxetine-treated patients and for the placebo group: least squares (LS) mean change from baseline in BPI-Severity average pain score at Week 14; LS mean change from baseline in BPI-Severity average pain score at Weeks 2, 4, 6, and 10; proportion of patients with $\geq 30 \%$ (corresponding to moderate improvement) ${ }^{13}$ or $\geq 50 \%$ (corresponding to substantial improvement $)^{13}$ reduction in BPI-Severity average pain score at Week 14; LS mean change from baseline in BPI-Interference scores ${ }^{14}$ (general activity, mood, walking ability, normal work, relationships with other people, sleep, and enjoyment of life, and the average of the seven domains, each rated from 0 [does not interfere] to 10 [completely interferes]); LS mean 
change from baseline in OA-specific QOL assessed using the Western Ontario and McMaster Universities Osteoarthritis Index (WOMAC) ${ }^{15}$ and LS mean Patient Global Impression of Improvement (PGI-I). ${ }^{16}$ The BPI-Interference, WOMAC, and PGI-I scores were measured at Weeks 0 (except PGI-I), 2, $4,6,10$, and 14. We also assessed the time of occurrence and time to resolution of the six TR-AESIs in the duloxetine group.

\section{Statistical analysis}

Analysis was performed on the full analysis set, which consisted of all randomized patients who received $\geq 1$ dose of the study drug and had post-baseline BPI-Severity average pain score data available. Baseline characteristics were compared by one-way ANOVA (continuous variables) or Fisher's exact test (categorical variables). LS mean change from baseline data were compared between the duloxetine subgroups and the placebo group at each time point using a mixed-effects model repeated measures approach, in which the model included subgroup, time point, and subgroup-by-time point interaction as the fixed effects and baseline value as a covariate. The proportions of patients with $\geq 30 \%$ or $\geq 50 \%$ reduction in BPI-Severity average pain score at Week 14 were compared between each duloxetine subgroup and the placebo group by the Cochran-Mantel-Haenszel test and were adjusted by the allocation factor (baseline BPI-Severity average pain score $<6$ or $\geq 6$ ). In the responder analysis, missing data were imputed using the last observation carried forward approach. Differences were considered to be statistically significant if $P<0.05$. All statistical analyses were carried out using SAS version 9.2 (SAS Institute, Cary, NC, USA).

\section{Results}

\section{Early improvement in pain}

\section{Baseline characteristics}

Of 177 patients treated with duloxetine, 93 (54\%) had $\geq 30 \%$ pain reduction, $45(26 \%)$ had $10 \%-30 \%$ pain reduction, and $33(19 \%)$ had $<10 \%$ pain reduction at Week $4 ; 6$ patients withdrew from the study within the first 2 weeks and were not included in the early pain improvement analysis. Baseline characteristics were generally similar between subgroups, although the BPI-Severity average pain score was lower in the $<10 \%$ subgroup compared with the other groups (Table 1).

\section{BPI-Severity average pain score}

Patients in the $\geq 30 \%$ early improvement subgroup had significantly greater decreases from baseline in BPI-Severity average pain compared with the placebo group at Week 14, as well as at Weeks 2, 4, 6, and 10 (Figure 1). There were no significant differences in the change from baseline in BPI-Severity average pain score between the $10 \%-30 \%$ early improvement subgroup and the placebo group at any time point. Patients in the $<10 \%$ early improvement subgroup had significantly smaller decreases from baseline in BPI-Severity average pain score compared with the placebo group at Weeks 4 and 6.

\section{Response rate}

Pain responses at Week 14 reflected the pain responses at Week 4 (Figure S1). Week 14 response rates for both $\geq 30 \%$ and $\geq 50 \%$ pain reduction were significantly higher in the $\geq 30 \%$ early improvement subgroup compared with

Table I Demographics and baseline disease characteristics of patients with $\geq 30 \%, 10 \%-30 \%$, and $<10 \%$ reduction in BPI-Severity average pain score at Week 4

\begin{tabular}{|c|c|c|c|c|c|c|c|}
\hline \multirow[t]{2}{*}{ Characteristic } & \multicolumn{6}{|c|}{$\begin{array}{l}\text { Duloxetine } 60 \mathrm{mg} \text { QD } \\
\text { BPI-Severity average pain score reduction at Week } 4\end{array}$} & \multirow[t]{2}{*}{$P$-value } \\
\hline & $\begin{array}{l}\geq 30 \% \\
(n=93)\end{array}$ & $\begin{array}{l}10 \%-30 \% \\
(n=45)\end{array}$ & $\begin{array}{l}<10 \% \\
(n=33)\end{array}$ & $\begin{array}{l}\text { Withdrawal } \\
(n=6)\end{array}$ & $\begin{array}{l}\text { Placebo } \\
(n=176)\end{array}$ & $\begin{array}{l}\text { Overall } \\
(N=353)\end{array}$ & \\
\hline \multicolumn{7}{|l|}{ Sex, n (\%) } & $0.676 \mathrm{I}^{\mathrm{a}}$ \\
\hline Male & $18(19.4)$ & $10(22.2)$ & $7(21.2)$ & $0(0.0)$ & $44(25.0)$ & $79(22.4)$ & \\
\hline Female & $75(80.6)$ & $35(77.8)$ & $26(78.8)$ & $6(100.0)$ & $132(75.0)$ & $274(77.6)$ & \\
\hline Age, mean (SD), years & $64.8(8.2)$ & $66.1(8.4)$ & $67.3(6.7)$ & $61.8(8.1)$ & $66.4(8.4)$ & $65.9(8.2)$ & $0.3192^{\mathrm{b}}$ \\
\hline Body weight, mean (SD), kg & $63.20(13.71)$ & $63.31(12.70)$ & $61.06(11.11)$ & $59.52(10.15)$ & $62.56(11.53)$ & $62.63(12.19)$ & $0.8652^{\mathrm{b}}$ \\
\hline \multicolumn{7}{|c|}{ Use of NSAIDs in past 3 months, ${ }^{c} n(\%)$} & $0.7432^{\mathrm{a}}$ \\
\hline Yes & $51(54.8)$ & $25(55.6)$ & $17(5 \mid .5)$ & $5(83.3)$ & $100(56.8)$ & $198(56.1)$ & \\
\hline No & $42(45.2)$ & $20(44.4)$ & $16(48.5)$ & I (I6.7) & $76(43.2)$ & $155(43.9)$ & \\
\hline \multicolumn{7}{|l|}{ BPI-Severity average pain score } & $0.0163^{\mathrm{b}}$ \\
\hline Mean (SD) & $5.2(1.0)$ & $5.0(1.0)$ & $4.5(0.7)$ & $5.0(0.9)$ & $5.1(1.0)$ & $5.0(1.0)$ & \\
\hline$<6, \mathrm{n}(\%)$ & $57(6 \mid .3)$ & $35(77.8)$ & $29(87.9)$ & $4(66.7)$ & $124(70.5)$ & $249(70.5)$ & \\
\hline$\geq 6, n(\%)$ & 36 (38.7) & $10(22.2)$ & $4(12.1)$ & $2(33.3)$ & $52(29.5)$ & $104(29.5)$ & \\
\hline
\end{tabular}

Notes: a'Fisher's exact test (global comparison across subgroups). ${ }^{b}$ One-way ANOVA (global comparison across subgroups). 'Use of NSAIDs for at least I4 days per month within the past 3 months before the study start.

Abbreviations: BPI, Brief Pain Inventory; NSAIDs, nonsteroidal anti-inflammatory drugs; QD, once daily. 


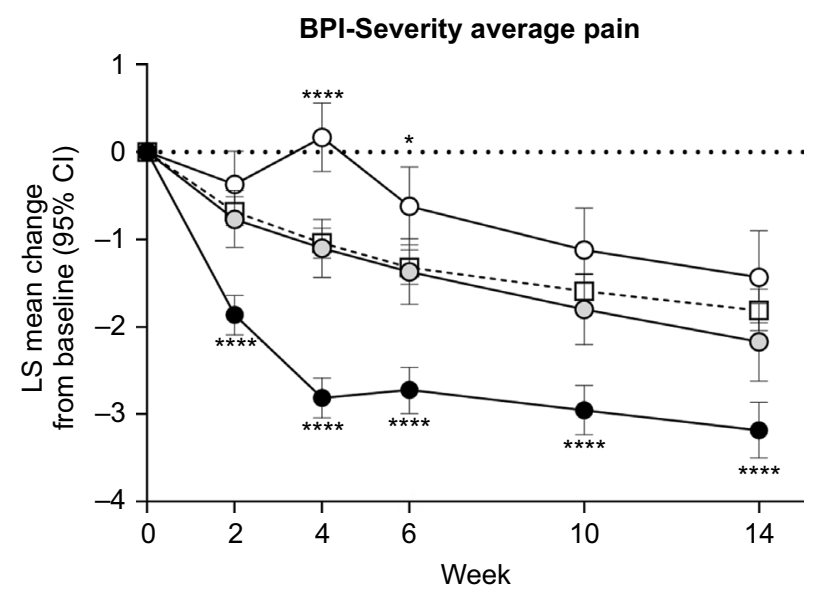

Figure I LS mean $(95 \% \mathrm{Cl})$ change from baseline in BPI-Severity average pain score through Week 14 in patients treated with placebo (white squares) or duloxetine. Notes: Duloxetine subgroups are patients with $\geq 30 \%$ (black circles), 10\%-30\% (gray circles), or $<10 \%$ (white circles) pain reduction at Week 4 . $* P<0.05, * * * * P<0.000$ I compared with placebo.

Abbreviations: BPI, Brief Pain Inventory; LS, least squares.

the placebo group. There were no significant differences in response rates between the $10 \%-30 \%$ or the $<10 \%$ early improvement subgroups and the placebo group.

\section{BPI-Interference scores}

Patients in the $\geq 30 \%$ early improvement subgroup had significantly greater decreases from baseline in BPI-Interference scores compared with the placebo group for most domains at most time points (Figure 2). The only exceptions were relationships with others and enjoyment of life, which were not significant at Week 2. There were no significant differences in the change from baseline in BPI-Interference scores between the $10 \%-30 \%$ or the $<10 \%$ early improvement subgroups and the placebo group for most domains and time points; exceptions were normal work at Week 10 and general activity, enjoyment of life, and the average of the seven domains at Week 14 in the $10 \%-30 \%$ subgroup.

\section{Western Ontario and McMaster Universities Osteoarthritis Index}

Patients in the $\geq 30 \%$ early improvement subgroup had significantly greater decreases from baseline in the WOMAC total score and all subscores at all time points compared with the placebo group (Figure 3). For patients with 10\%-30\% early improvement, significantly greater decreases than placebo were apparent for the WOMAC total score, stiffness subscore, and physical function subscore at Weeks 10 and 14 , and the WOMAC pain subscore at Week 14. For patients with $<10 \%$ early improvement, significantly greater decreases than placebo were apparent for the WOMAC total score at
Weeks 10 and 14, and for the WOMAC stiffness subscore at Weeks 2, 10, and 14 .

\section{Patient Global Impression of Improvement}

Patients in the $\geq 30 \%$ early improvement subgroup had significantly greater improvements in PGI-I compared with the placebo group at all time points (Figure 4). Patients in the $10 \%-30 \%$ early improvement subgroup had significantly greater improvements in PGI-I compared with the placebo group at Week 10. There were no significant differences in PGI-I between the $<10 \%$ early improvement subgroup and the placebo group.

\section{Early TR-AESIs \\ Pattern of TR-AESIs}

Most TR-AESIs were reported within the first 2 weeks of duloxetine treatment (Figure S2). The duration of TR-AESIs was variable; however, more than half $(55 \%)$ of the events continued for 4 weeks or longer. Most events were not severe. ${ }^{8}$

\section{Baseline characteristics}

Of 177 patients treated with duloxetine, 52 (29\%) had a TRAESI within the first 2 weeks of treatment. Baseline characteristics were similar between patients with and without early TR-AESIs (Table 2).

\section{BPI-Severity average pain score}

Pain improved in patients in both subgroups, regardless of the presence or absence of early TR-AESIs. Patients in both TR-AESI subgroups had significantly greater decreases from baseline in BPI-Severity average pain compared with the placebo group at all time points (Figure 5). The magnitude of decrease was numerically greater for patients with early TR-AESIs compared with patients without early TR-AESIs at all time points.

\section{Response rate}

Patients in both TR-AESI subgroups had significantly higher pain response rates at Week 14 compared with those in the placebo group (Figure S3).

\section{BPI-Interference scores}

Patients in both TR-AESI subgroups had significantly greater decreases from baseline in BPI-Interference scores compared with the placebo group in most domains at certain time points (Figure 6). For patients with early TR-AESIs, significantly greater decreases were apparent for general activity and normal work at all time points, walking ability at all time 


\section{BPI-Interference}

A

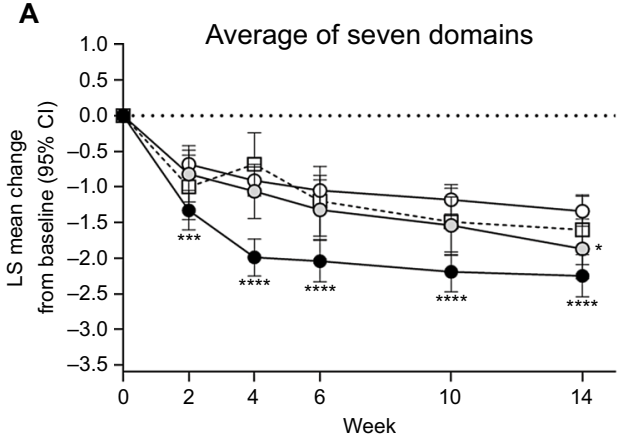

C

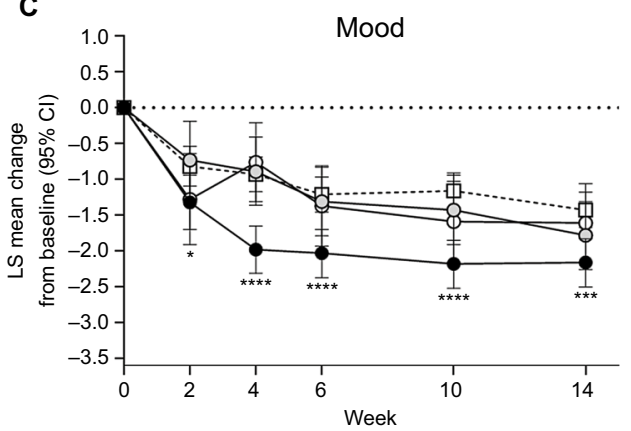

E

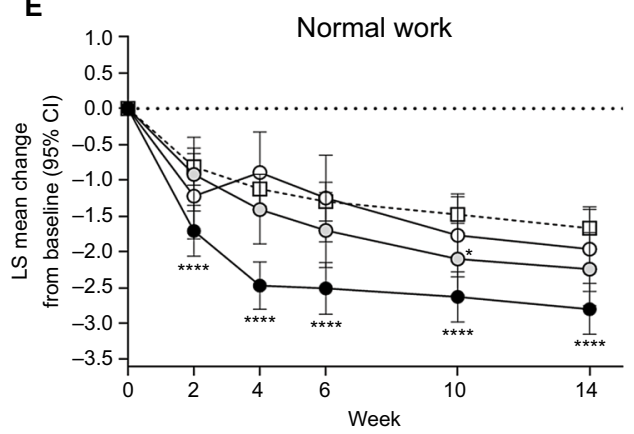

G

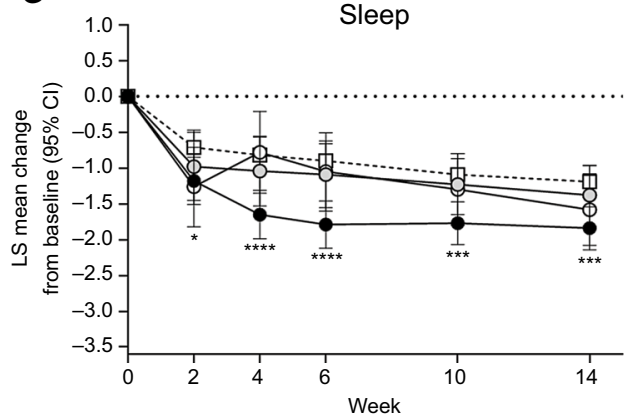

B

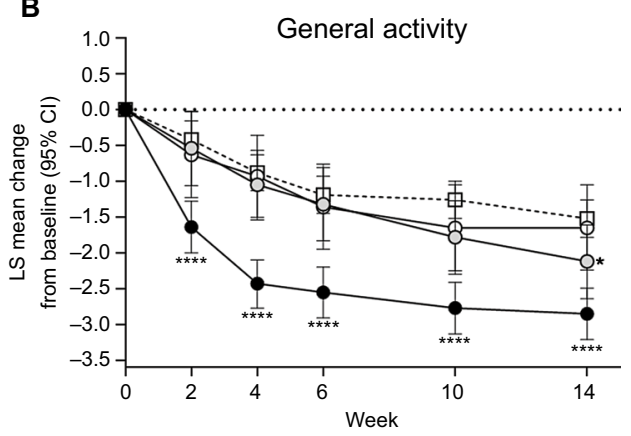

D

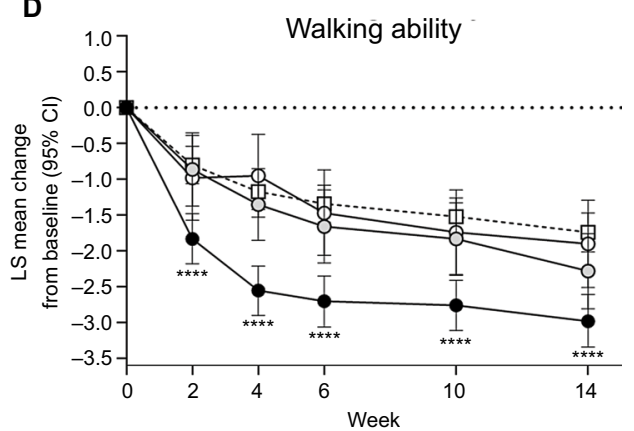

F

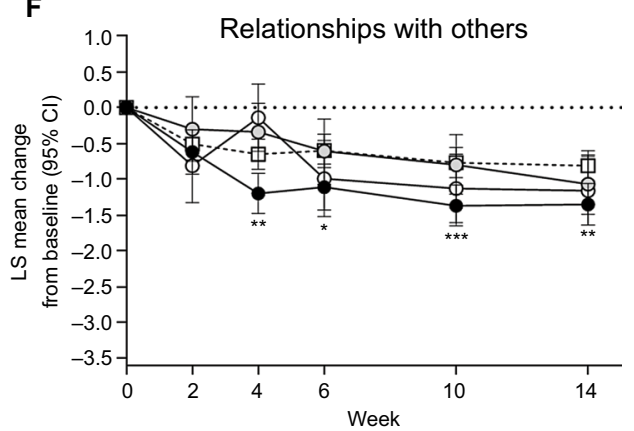

H

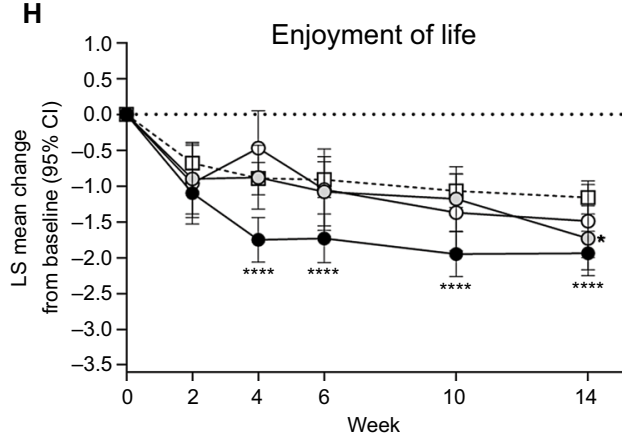

Figure 2 LS mean $(95 \% \mathrm{Cl})$ change from baseline in BPI-Interference domains through Week 14 in patients treated with placebo (white squares) or duloxetine. BPIInterference domains included general activity $(\mathbf{B})$, mood $(\mathbf{C})$, walking ability $(\mathbf{D})$, normal work (E), relationships with others $(\mathbf{F})$, sleep $(\mathbf{G})$, and enjoyment of life $(\mathbf{H})$, and the average of the seven domains (A).

Notes: Duloxetine subgroups are patients with $\geq 30 \%$ (black circles), $10 \%-30 \%$ (gray circles), or $<10 \%$ (white circles) pain reduction at Week 4 . $* P<0.05$, $* * P<0.01$, $* * * P \leq 0.001$, ****P $\leq 0.000$ I compared with placebo.

Abbreviations: BPI, Brief Pain Inventory; LS, least squares. 
WOMAC

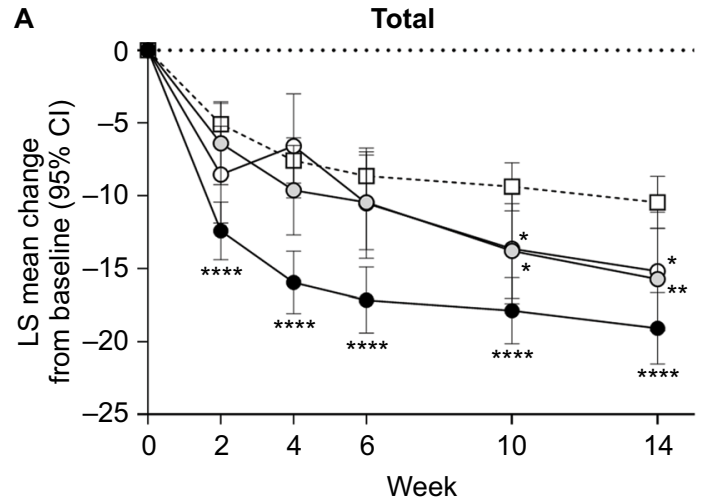

C

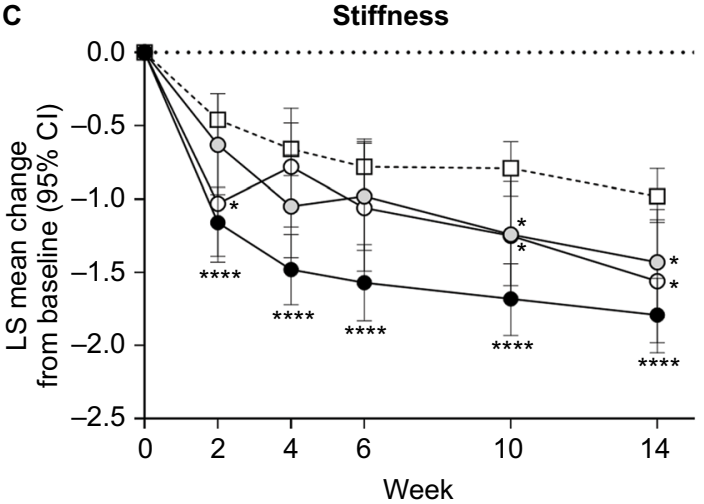

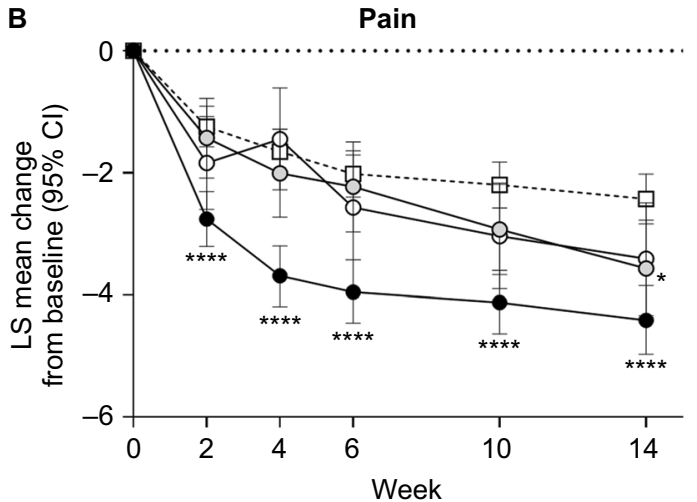

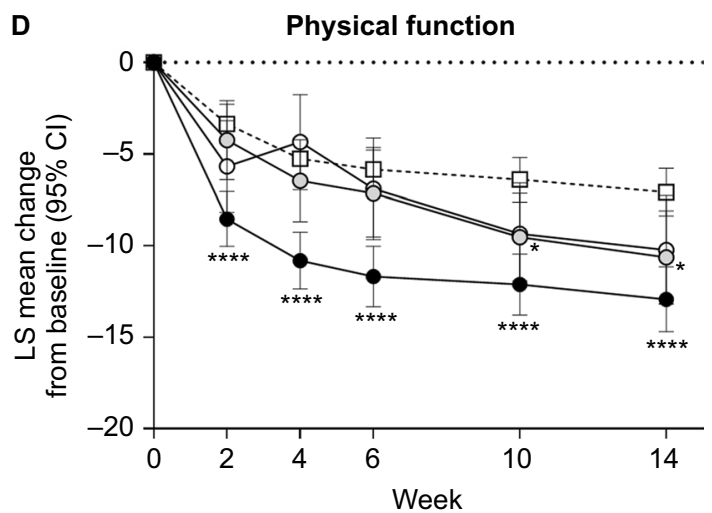

Figure 3 LS mean $(95 \% \mathrm{Cl})$ change from baseline in WOMAC total (A), pain (B), stiffness (C), and physical function (D) scores through Week I4 in patients treated with placebo (white squares) or duloxetine.

Notes: Duloxetine subgroups are patients with $\geq 30 \%$ (black circles), $10 \%-30 \%$ (gray circles), or $<10 \%$ (white circles) pain reduction at Week 4 . $* P<0.05$, $* * P<0.0$ I, $* * * * P<0.0001$ compared with placebo.

Abbreviations: LS, least squares; WOMAC, Western Ontario and McMaster Universities Osteoarthritis Index.

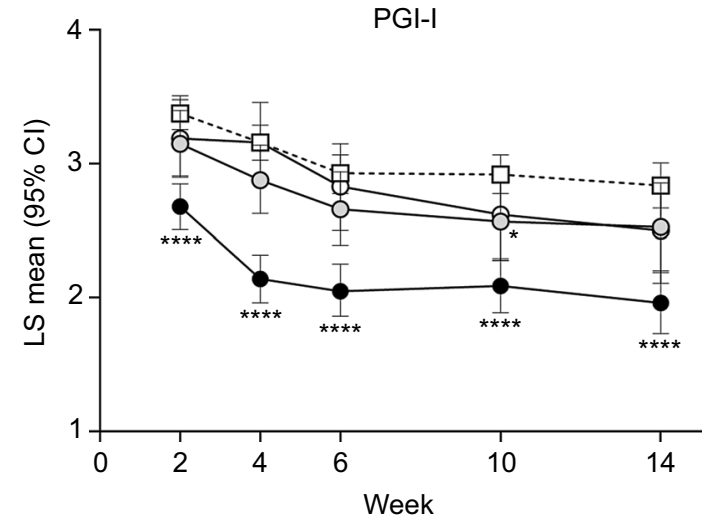

Figure 4 LS mean $(95 \% \mathrm{Cl})$ PGI-I scores through Week 14 in patients treated with placebo (white squares) or duloxetine.

Notes: Duloxetine subgroups are patients with $\geq 30 \%$ (black circles), 10\%-30\% (gray circles), or $<10 \%$ (white circles) pain reduction at Week 4 . $* P<0.05, * * * * P<0.000$ I compared with placebo.

Abbreviations: LS, least squares; PGI-I, Patient Global Impression of Improvement. points except Week 2, mood and relationships with others at Weeks 6, 10, and 14, sleep at Week 6, and enjoyment of life at Weeks 10 and 14. The average of the seven domains was significantly greater than placebo at Weeks 4, 6, 10, and 14 . For patients without early TR-AESIs, significantly greater decreases were apparent for all domains and all time points, except for relationships with others, which was significant only at Week 14, and enjoyment of life, which was not significant only at Week 4 .

\section{Western Ontario and McMaster Universities Osteoarthritis Index}

Patients in both TR-AESI subgroups had significantly greater decreases from baseline in WOMAC total and all subscores compared with the placebo group at all time points (Figure 7). 
Table 2 Demographics and baseline disease characteristics of patients with and without TR-AESIs (nausea, somnolence, constipation, thirst, malaise, or decreased appetite) in the first 2 weeks

\begin{tabular}{|c|c|c|c|c|c|}
\hline \multirow[t]{2}{*}{ Characteristic } & \multicolumn{4}{|c|}{ Duloxetine 60 mg QD } & \multirow[t]{2}{*}{$P$-value } \\
\hline & $\begin{array}{l}\text { With TR-AESIs } \\
\text { by Week } 2(n=52)\end{array}$ & $\begin{array}{l}\text { Without TR-AESIs } \\
\text { by Week } 2(n=125)\end{array}$ & $\begin{array}{l}\text { Placebo } \\
(n=176)\end{array}$ & $\begin{array}{l}\text { Overall } \\
(\mathrm{N}=353)\end{array}$ & \\
\hline Sex, n (\%) & & & & & $0.2178^{\mathrm{a}}$ \\
\hline Male & 7 (13.5) & $28(22.4)$ & $44(25.0)$ & $79(22.4)$ & \\
\hline Female & $45(86.5)$ & $97(77.6)$ & $132(75.0)$ & $274(77.6)$ & \\
\hline Age, mean (SD), years & $67.0(7.1)$ & $64.9(8.3)$ & $66.4(8.4)$ & $65.9(8.2)$ & $0.1773^{b}$ \\
\hline Body weight, mean (SD), kg & $61.49(13.08)$ & $63.21(12.77)$ & $62.56(11.53)$ & $62.63(12.19)$ & $0.692 I^{b}$ \\
\hline Use of NSAIDs in past 3 months, ${ }^{c} n(\%)$ & & & & & $0.222 I^{\mathrm{a}}$ \\
\hline Yes & $34(65.4)$ & $64(5 \mid .2)$ & $100(56.8)$ & $198(56.1)$ & \\
\hline No & $18(34.6)$ & $61(48.8)$ & $76(43.2)$ & $155(43.9)$ & \\
\hline BPI-Severity average pain score & & & & & $0.6066^{\mathrm{b}}$ \\
\hline Mean (SD) & $4.9(0.9)$ & $5.1(1.0)$ & $5.1(1.0)$ & $5.0(1.0)$ & \\
\hline$<6, \mathrm{n}(\%)$ & $4 \mathrm{I}(78.8)$ & $84(67.2)$ & $124(70.5)$ & $249(70.5)$ & \\
\hline$\geq 6, \mathrm{n}(\%)$ & II (2I.2) & $41(32.8)$ & $52(29.5)$ & $104(29.5)$ & \\
\hline
\end{tabular}

Notes: 'Fisher's exact test (global comparison across subgroups). ' $\mathrm{O}$ One-way ANOVA (global comparison across subgroups). 'Use of NSAIDs for at least 14 days per month within the past 3 months before the study start.

Abbreviations: BPI, Brief Pain Inventory; NSAIDs, nonsteroidal anti-inflammatory drugs; QD, once daily; TR-AESIs, treatment-related adverse events of special interest.

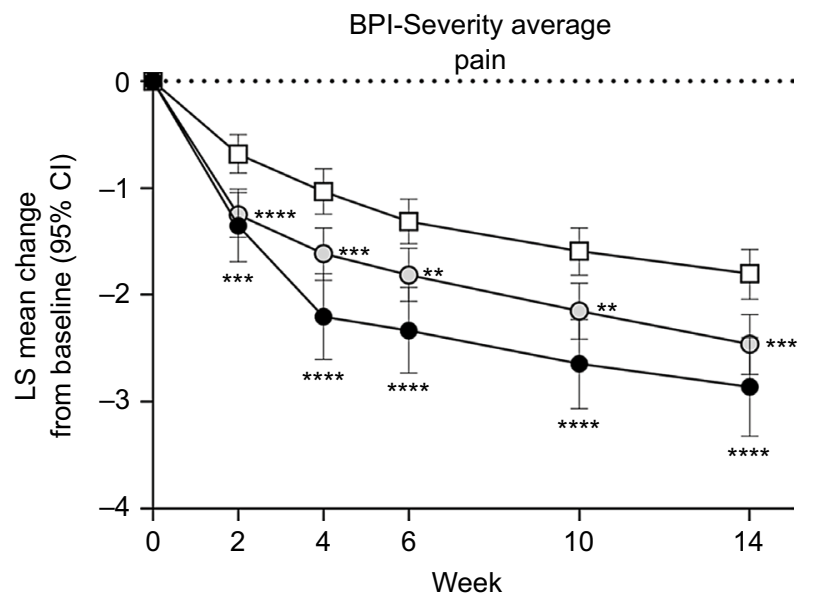

Figure $5 \mathrm{LS}$ mean $(95 \% \mathrm{Cl})$ change from baseline in BPI-Severity average pain score through Week 14 in patients treated with placebo (white squares) or duloxetine. Notes: Duloxetine subgroups are patients with (black circles) or without (gray circles) treatment-related adverse events of special interest between baseline and Week 2. $* * P<0.01$, $* * * P<0.00$ I, $* * * * P \leq 0.000$ I compared with placebo.

Abbreviations: BPI, Brief Pain Inventory; LS, least squares.

\section{Patient Global Impression of Improvement}

Patients in both TR-AESI subgroups had significantly greater improvements in PGI-I compared with the placebo group at all time points (Figure 8).

\section{Discussion}

This is the first post hoc analysis of a randomized, placebocontrolled trial to evaluate the relationship between early pain reduction or early TR-AESIs and later pain reduction, improvements in QOL, and PGI-I after treatment with duloxetine in Japanese patients with OA knee pain.
Notably, patients who had $\geq 30 \%$ pain reduction at 4 weeks of duloxetine treatment had significantly greater pain reduction and improvements in QOL relative to placebo at later time points (ie, at 6,10, and/or 14 weeks), whereas patients with $<30 \%$ early pain reduction did not. These findings suggest that monitoring pain reduction during the first 4 weeks of duloxetine treatment may help physicians determine if patients with OA knee pain are likely to benefit from continued treatment. In particular, patients who do not experience $\geq 30 \%$ pain reduction after 4 weeks of duloxetine are unlikely to respond during the subsequent 10 weeks. In contrast to early pain reduction, early TR-AESIs were not predictive of pain response: improvements in pain and QOL relative to placebo were seen in all patients regardless of whether they experienced TR-AESIs during the first 2 weeks of duloxetine treatment.

As noted, we found that patients who had early reduction in pain ( $\geq 30 \%$ reduction at Week 4$)$ in response to treatment with duloxetine experienced greater improvements in pain that were sustained for 14 weeks than patients who did not have early pain reduction. Similar findings of early pain response predicting later improvement in pain have been reported in patients with $\mathrm{CLBP}^{11}$ and fibromyalgia. ${ }^{17}$ Our findings are also consistent with those of a post hoc analysis of placebo-controlled trials showing that patients with CLBP or OA knee pain who experienced minimal $(<10 \%)$ early (at 4 weeks) improvement in pain have a limited possibility of achieving at least moderate improvement in pain after 12 weeks of duloxetine treatment. ${ }^{18}$ Taken together, these findings suggest that an early pain response may be a good 


\section{BPI-Interference}
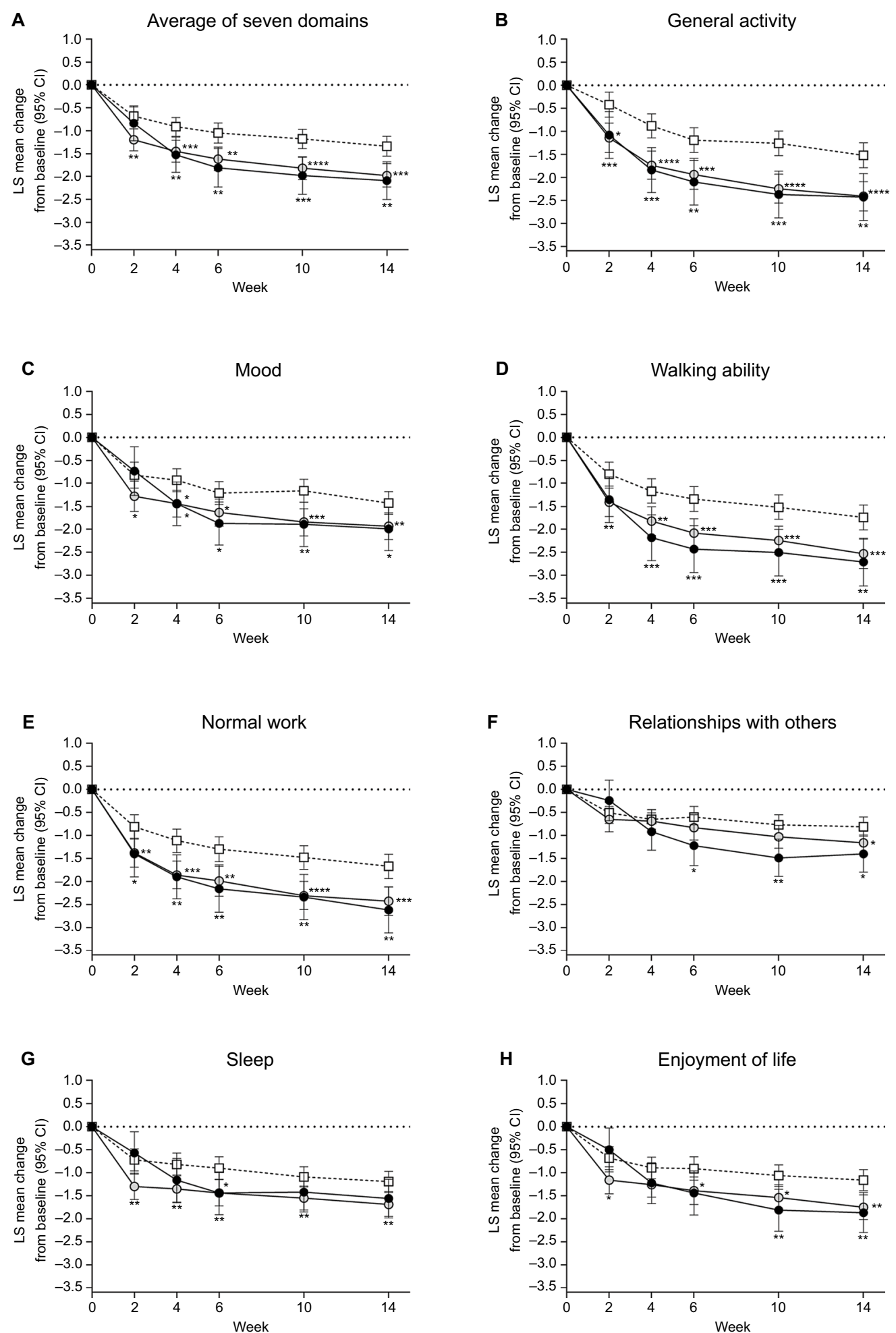

Figure $6 \mathrm{LS}$ mean $(95 \% \mathrm{Cl})$ change from baseline in BPI-Interference domains through Week I4 in patients treated with placebo (white squares) or duloxetine. BPIInterference domains included general activity $(\mathbf{B})$, mood $(\mathbf{C})$, walking ability $(\mathbf{D})$, normal work $(\mathbf{E})$, relationships with others $(\mathbf{F})$, sleep $(\mathbf{G})$, and enjoyment of life $(\mathbf{H})$, and the average of the seven domains $(\mathbf{A})$.

Notes: Duloxetine subgroups are patients with (black circles) or without (gray circles) treatment-related adverse events of special interest between baseline and Week 2. $* P<0.05, * * P<0.01, * * * P<0.001, * * * * P \leq 0.000$ I compared with placebo.

Abbreviations: BPI, Brief Pain Inventory; LS, least squares. 


\section{WOMAC}

A

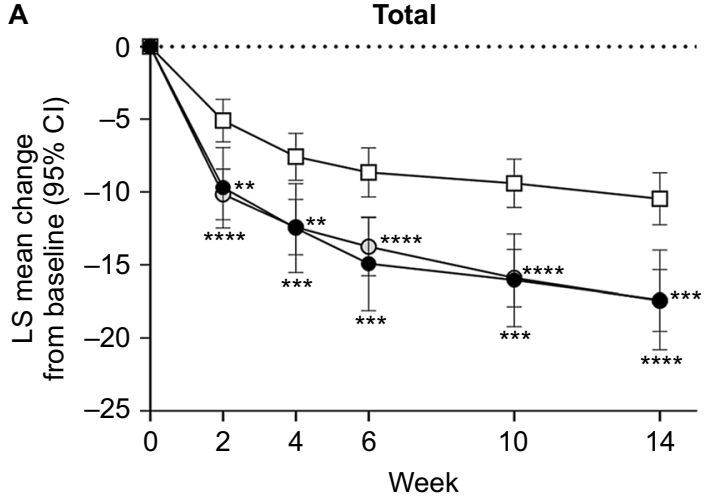

C

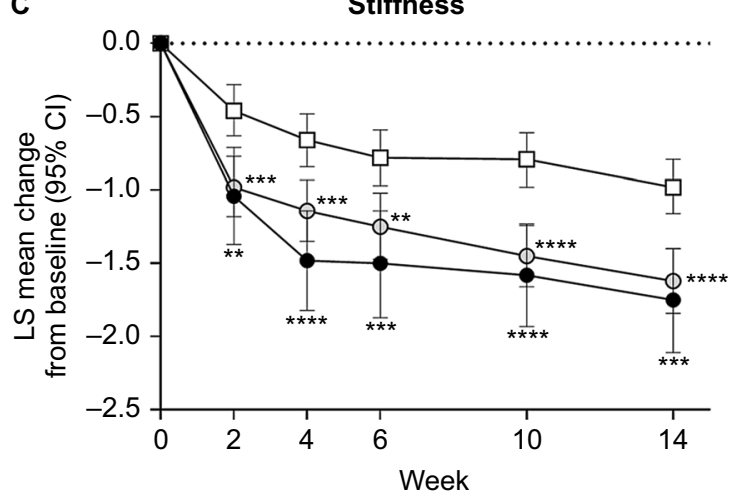

B
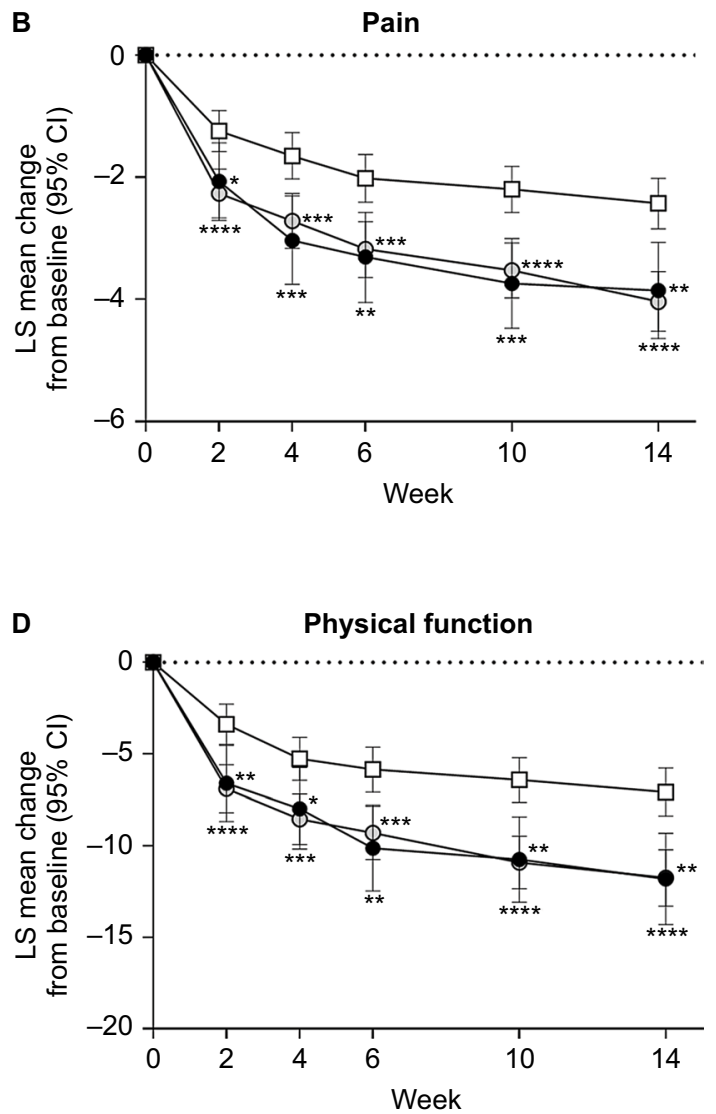

Figure 7 LS mean $(95 \% \mathrm{Cl})$ change from baseline in WOMAC total (A), pain (B), stiffness (C), and physical function (D) scores through Week I4 in patients treated with placebo (white squares) or duloxetine.

Notes: Duloxetine subgroups are patients with (black circles) or without (gray circles) treatment-related adverse events of special interest between baseline and Week 2. $* P<0.05$, **P $<0.01$, $* * * P<0.001$, ***** $P \leq 0.000$ I compared with placebo.

Abbreviations: LS, least squares; WOMAC, Western Ontario and McMaster Universities Osteoarthritis Index.

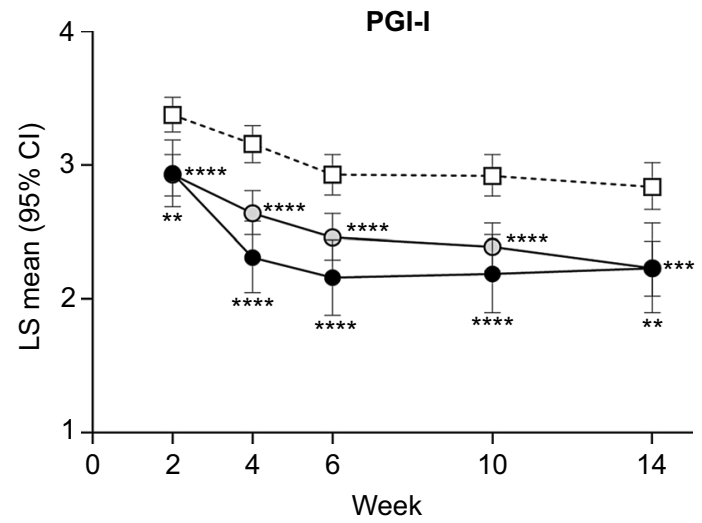

Figure 8 LS mean $(95 \% \mathrm{Cl})$ PGI-I scores through Week 14 in patients treated with placebo (white squares) or duloxetine.

Notes: Duloxetine subgroups were patients with (black circles) or without (gray circles) treatment-related adverse events of special interest between baseline and Week 2. $* * P<0.01$, $* * * P<0.001$, $* * * * P<0.000$ I compared with placebo.

Abbreviations: LS, least squares; PGI-I, Patient Global Impression of Improvement. indicator of a continued duloxetine treatment response in patients with OA knee pain. However, it should be noted that the baseline BPI-Severity average pain scores were lower in patients with $<10 \%$ early pain reduction compared with the other subgroups, which may have limited the extent of further improvement.

Interestingly, the WOMAC pain subscore and PGI-I results were consistent with the BPI-Severity average pain results; this is the first study to report this relationship between QOL and PGI-I. Patients with knee OA consider QOL as being a more important factor than pain relief in making them "feel better" ${ }^{19}$ In this study, we found that patients who had early pain responses to duloxetine treatment had greater improvements in QOL than patients who did not have early pain responses, consistent with the results of our 
previous CLBP analysis. ${ }^{11}$ Improvements were greatest for the BPI-Interference domains of general activity, walking ability, and normal work, indicating that improvement in OA knee pain led to improvement in physical function. Similarly, the WOMAC physical function domain was improved in patients who had early pain responses. Thus, early pain relief may be particularly important in improving movement and physical function in patients with pain due to musculoskeletal disorders, such as knee OA and CLBP.

In our previous analysis of patients with CLBP, ${ }^{11}$ we found that patients who had early TR-AESIs (within the first 2 weeks) had significantly greater improvements in pain and QOL after 14 weeks of duloxetine than patients treated with placebo. In contrast, in the current study, duloxetine-treated patients with knee OA experienced significant improvements in pain and QOL, as well as PGI-I, regardless of the presence or absence of early TR-AESIs. This observed difference between CLBP and knee OA in the relationship between early TR-AESIs and later pain reduction and QOL may reflect the greater contribution of psychosocial factors, such as catastrophizing, to pain perception and physical function in CLBP compared with OA. ${ }^{20-22}$ As up to $85 \%$ of CLBP is nonspecific and cannot be attributed to a known cause, ${ }^{23}$ the underlying etiology and mechanisms of pain are considered more complex than those of OA. Thus, the presence or absence of early TR-AESIs is more likely to influence the perception of pain and the consequent QOL in patients with CLBP than in patients with knee OA.

This analysis included data from a well-designed, randomized controlled trial that not only assessed pain reduction (by BPI-Severity average pain score), but also patient QOL (by both BPI-Interference and WOMAC scores) and PGI-I at multiple time points during the trial. However, in addition to its post hoc nature, the results are limited by the relatively short duration of treatment (14 weeks) and possible biases inherent to the analysis method. Further, the applicability of the results to non-Japanese populations will need to be confirmed.

\section{Conclusion}

This post hoc analysis suggests that the presence or absence of early efficacy responses (at 4 weeks) to duloxetine treatment may be indicative of the extent of pain reduction, QOL improvements, and overall patient impression of improvement at 14 weeks in Japanese patients with OA knee pain, as previously reported for patients with CLBP. ${ }^{11}$ However, unlike in patients with CLBP, the presence of early TR-AESIs was not a predictor of overall pain response to duloxetine.
Monitoring pain reduction within the first month of treatment may help physicians identify patients who are likely to gain the most benefit from continued duloxetine treatment.

\section{Acknowledgments}

This study was sponsored by Shionogi \& Co. Ltd, the manufacturer of duloxetine. Shionogi \& Co. Ltd was involved in the study design, data collection, data analysis, preparation of the manuscript, and the decision to submit this manuscript for publication. Medical writing assistance was provided by Rebecca Lew, PhD, CMPP and Hiroko Ebina, BPharm, Ph, MBA of ProScribe - Envision Pharma Group, and was funded by Shionogi \& Co. Ltd. ProScribe's services complied with the international guidelines for Good Publication Practice (GPP3).

\section{Author contributions}

All authors were study investigators and participated in the study design and interpretation of study results, and in the drafting, critical revision, and approval of the final version of the manuscript, and agree to be accountable for all aspects of the work. MI and TO were involved in data collection, and TO conducted the statistical analysis.

\section{Disclosure}

NI, TT, MI, and TO are full-time employees and minor stockholders in Shionogi \& Co. Ltd. YU has received honoraria/ consulting fees, travel support, fees for participation in review activities, fees for writing assistance, medicine, equipment, and administrative support, and/or grants from Shionogi \& Co., Ltd; Astellas Pharma Inc.; Asahi Kasei Pharma Corporation; Chugai Pharmaceutical Co., Ltd; Daiichi Sankyo Co., Ltd; Kaken Pharmaceutical Co., Ltd; Nippon Zoki Pharmaceutical Co., Ltd; Seikagaku Corporation; Taisho Toyama Pharmaceutical Co., Ltd; Teijin Pharma Limited; Pfizer Japan Inc.; Japan Tissue Engineering Co., Ltd; Ayumi Pharmaceutical Corporation; Hisamitsu Pharmaceutical Co., Inc.; HOYA Technosurgical Corporation; Mochida Pharmaceutical Co., Ltd; Eli Lilly Japan K.K.; Olympus Terumo Biomaterials Corporation; Janssen Pharmaceutical K.K.; Ministry of Economy, Trade, and Industry; Japan Science and Technology Agency; Japan Society for the Promotion of Science; Japan Sports Medicine Foundation; and the Terumo Foundation for Life Sciences and Arts. SK has received grants, honoraria, reviewing fees, payment for lectures, fees for writing assistance, medicines, equipment, and/or administrative support from Shionogi \& Co., Ltd; MSD K.K.; Asahi Kasei Pharma Corporation; Eli Lilly Japan K.K.; Eisai Co., Ltd; Ono Pharmaceutical Co., Ltd; Kaken Pharmaceutical Co., Ltd; Kowa Pharmaceutical Co., Ltd; Showa Yakuhin Kako 
Co., Ltd; Johnson \& Johnson K.K.; Daiichi Sankyo Co., Ltd; Taisho Toyama Pharmaceutical Co., Ltd; Takeda Pharmaceutical Co., Ltd; Terumo Corporation; Nippon Zoki Pharmaceutical Co., Ltd; Hisamitsu Pharmaceutical Co., Inc.; Pfizer Japan Inc.; Janssen Pharmaceutical K.K.; Ayumi Pharmaceutical Corporation; Taiho Pharmaceutical Co., Ltd; Chugai Pharmaceutical Co., Ltd; Teijin Pharma Limited; Astellas Pharma Inc.; Nippon Shinyaku Co., Ltd; Stryker Japan K.K.; Tsumura \& Co.; and Otsuka Pharmaceutical Co., Ltd. The authors report no other conflicts of interest in this work.

\section{References}

1. GBD 2015 Disease and Injury Incidence and Prevalence Collaborators. Global, regional, and national incidence, prevalence, and years lived with disability for 310 diseases and injuries, 1990-2015: a systematic analysis for the Global Burden of Disease Study 2015. Lancet. 2016;388(10053):1545-1602.

2. Litwic A, Edwards MH, Dennison EM, Cooper C. Epidemiology and burden of osteoarthritis. Br Med Bull. 2013;105:185-199.

3. Muraki S, Oka H, Akune T, et al. Prevalence of radiographic knee osteoarthritis and its association with knee pain in the elderly of Japanese population-based cohorts: the ROAD study. Osteoarthritis Cartilage. 2009;17(9):1137-1143.

4. Xie F, Kovic B, Jin X, He X, Wang M, Silvestre C. Economic and humanistic burden of osteoarthritis: a systematic review of large sample studies. Pharmacoeconomics. 2016;34(11):1087-1100.

5. Vignon E, Valat JP, Rossignol M, et al. Osteoarthritis of the knee and hip and activity: a systematic international review and synthesis (OASIS). Joint Bone Spine. 2006;73(4):442-455.

6. Altman RD. Early management of osteoarthritis. Am J Manag Care. 2010;16(Suppl Management):S41-47.

7. Konno S, Oda N, Ochiai T, Alev L. Randomized, double-blind, placebocontrolled Phase III trial of duloxetine monotherapy in Japanese patients with chronic low back pain. Spine. 2016;41(22):1709-1717.

8. Uchio Y, Enomoto H, Alev L, et al. A randomized, double-blind, placebocontrolled Phase III trial of duloxetine in Japanese patients with knee pain due to osteoarthritis. J Pain Res. 2018;11:809-821.

9. Yasuda H, Hotta N, Nakao K, Kasuga M, Kashiwagi A, Kawamori R. Superiority of duloxetine to placebo in improving diabetic neuropathic pain: Results of a randomized controlled trial in Japan. $J$ Diabetes Investig. 2011;2(2):132-139.
10. Moore RA, Cai N, Skljarevski V, Tölle TR. Duloxetine use in chronic painful conditions - individual patient data responder analysis. Eur $J$ Pain. 2014;18(1):67-75.

11. Tsuji T, Itoh N, Ishida M, Ochiai T, Konno S. Response to duloxetine in chronic low back pain: exploratory post hoc analysis of a Japanese Phase III randomized study. J Pain Res. 2017;10:2157-2168.

12. Altman R, Asch E, Bloch D, et al. Development of criteria for the classification and reporting of osteoarthritis. Classification of osteoarthritis of the knee. Diagnostic and Therapeutic Criteria Committee of the American Rheumatism Association. Arthritis Rheum. 1986;29(8):1039-1049.

13. Dworkin RH, Turk DC, Wyrwich KW, et al. Interpreting the clinical importance of treatment outcomes in chronic pain clinical trials: IMMPACT recommendations. J Pain. 2008;9(2):105-121.

14. Uki J, Mendoza T, Cleeland CS, Nakamura Y, Takeda F. A brief cancer pain assessment tool in Japanese: the utility of the Japanese Brief Pain Inventory-BPI-J. J Pain Symptom Manage. 1998;16(6):364-373.

15. Hashimoto H, Hanyu T, Sledge CB, Lingard EA. Validation of a Japanese patient-derived outcome scale for assessing total knee arthroplasty: comparison with Western Ontario and McMaster Universities osteoarthritis index (WOMAC). J Orthop Sci. 2003;8(3):288-293.

16. Guy W. ECDEU Assessment Manual for Psychopharmacology. Rockville: National Institute of Mental Health; 1976:76-338.

17. Wang F, Ruberg SJ, Gaynor PJ, Heinloth AN, Arnold LM. Early improvement in pain predicts pain response at endpoint in patients with fibromyalgia. J Pain. 2011;12(10):1088-1094.

18. Williamson OD, Schroer M, Ruff DD, et al. Onset of response with duloxetine treatment in patients with osteoarthritis knee pain and chronic low back pain: a post hoc analysis of placebo-controlled trials. Clin Ther. 2014;36(4):544-551.

19. Tallon D, Chard J, Dieppe P. Exploring the priorities of patients with osteoarthritis of the knee. Arthritis Care Res. 2000;13(5):312-319.

20. Baert IAC, Meeus M, Mahmoudian A, Luyten FP, Nijs J, Verschueren SMP. Do psychosocial factors predict muscle strength, pain, or physical performance in patients with knee osteoarthritis? J Clin Rheumatol. 2017;23(6):308-316.

21. Marshall PWM, Schabrun S, Knox MF. Physical activity and the mediating effect of fear, depression, anxiety, and catastrophizing on pain related disability in people with chronic low back pain. PLoS One. 2017;12(7):e0180788.

22. Moseley GL. Evidence for a direct relationship between cognitive and physical change during an education intervention in people with chronic low back pain. Eur J Pain. 2004;8(1):39-45.

23. Chou R, Qaseem A, Snow V, et al. Diagnosis and treatment of low back pain: a joint clinical practice guideline from the American College of Physicians and the American Pain Society. Ann Intern Med. 2007;147(7):478-491. 


\section{Supplementary materials}

\section{List of Institutional Review Boards:}

Ethics Committee on Clinical Trial of Shionogi

Aino Clinic Institutional Review Board

Tokyo Midtown Clinic Institutional Review Board

Medical Corporation EIYUKAI YASUDA Hospital Institutional Review Board

Sakayori Clinic Institutional Review Board

Sugiura Clinic Institutional Review Board

Onishi Medical Clinic Institutional Review Board

Maebashi Hirosegawa Clinic Institutional Review Board

Clinical Research Hospital Tokyo Institutional Review Board

Oita Central Institutional Review Board

Nakatani Hospital Institutional Review Board

Review Board of Human Rights and Ethics for Clinical Study Institutional Review Board

Fukui General Hospital Institutional Review Board

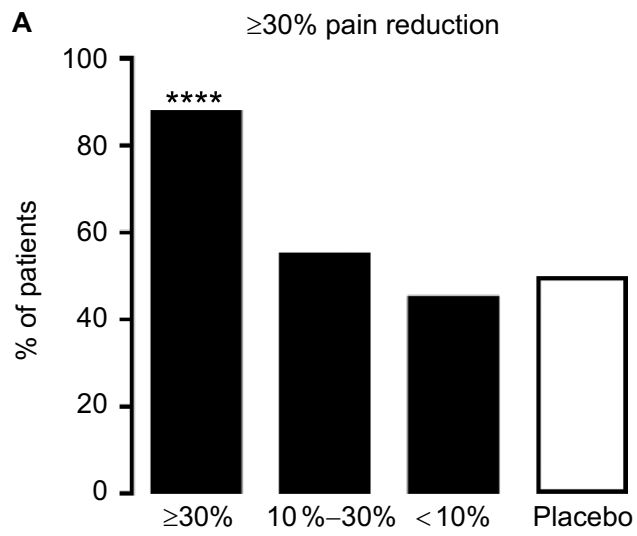

Pain reduction at Week 4 Duloxetine $60 \mathrm{mg} / \mathrm{day}$

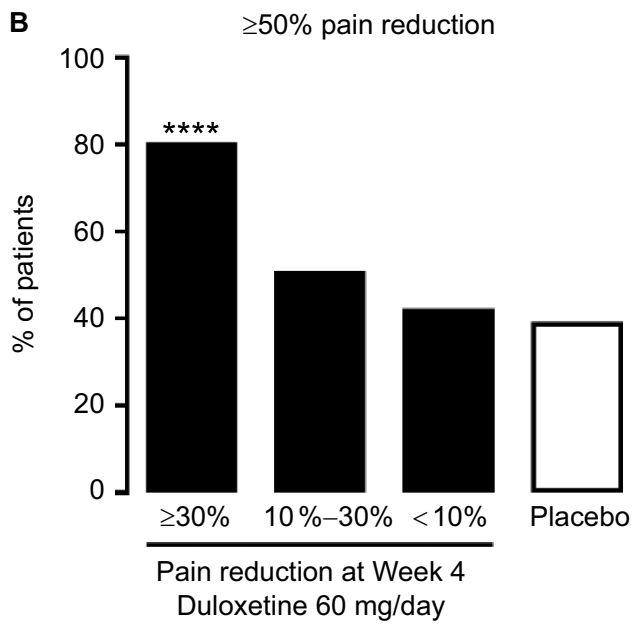

Figure SI Proportion of patients who achieved $\geq 30 \%$ (A) or $\geq 50 \%$ (B) pain reduction after 14 weeks of treatment with placebo or duloxetine.

Notes: Duloxetine subgroups are patients with $\geq 30 \%, 10 \%-30 \%$, or $<10 \%$ pain reduction at Week 4 . $* * * * P<0.000$ I compared with placebo. 


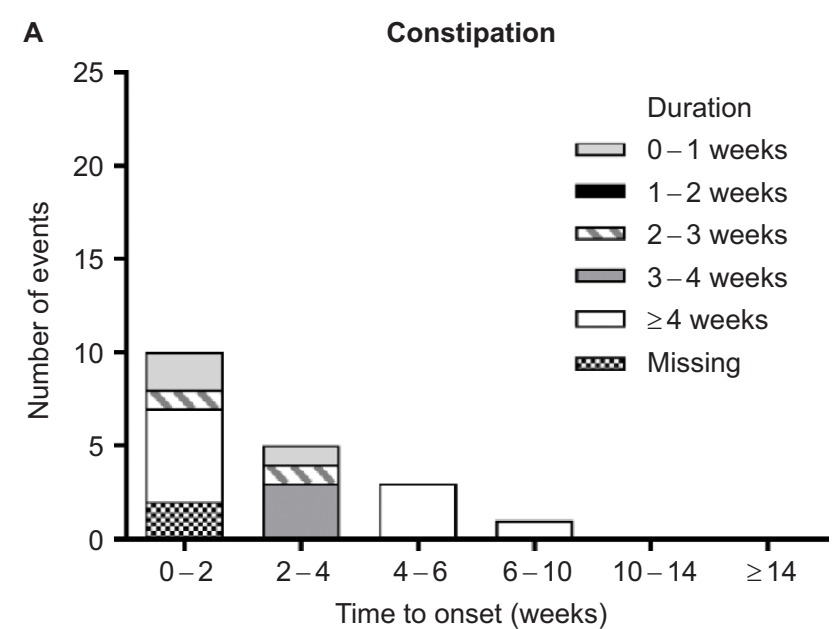

C

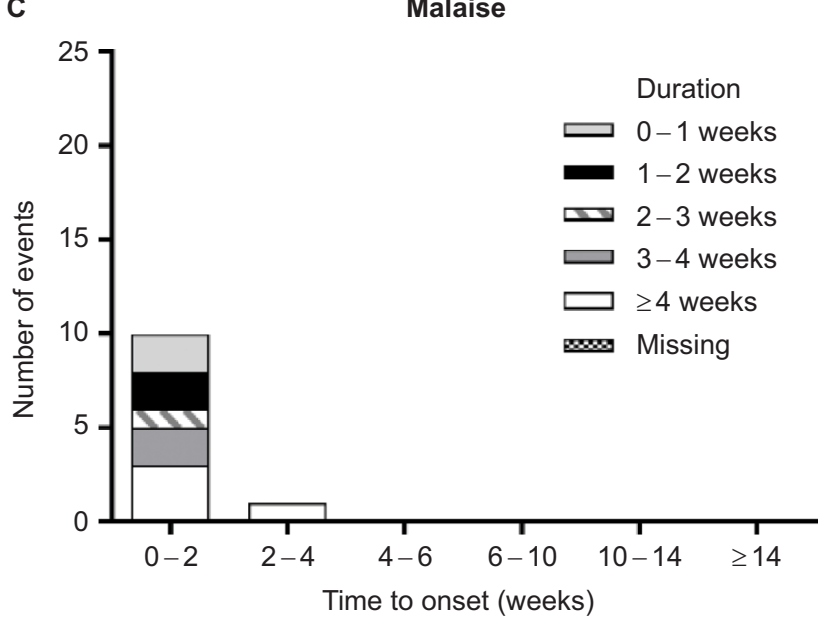

E

Somnolence

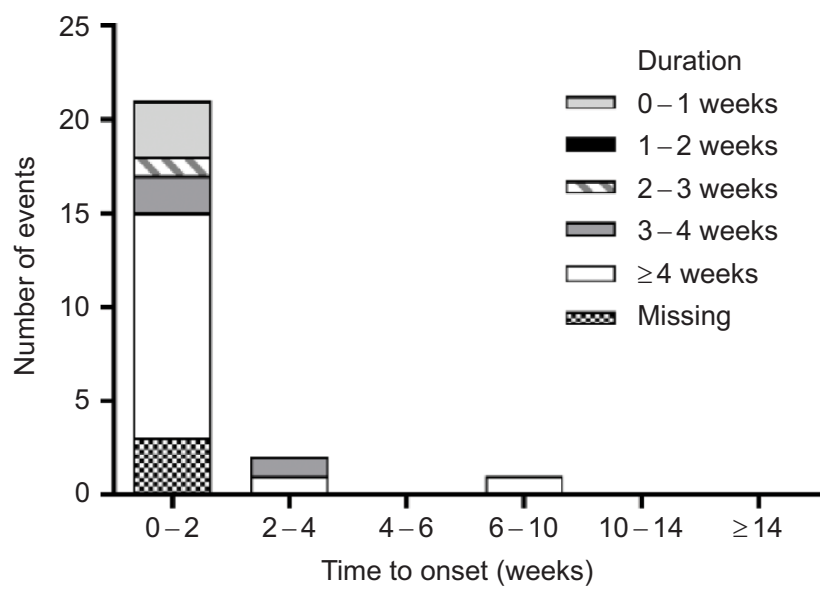

B

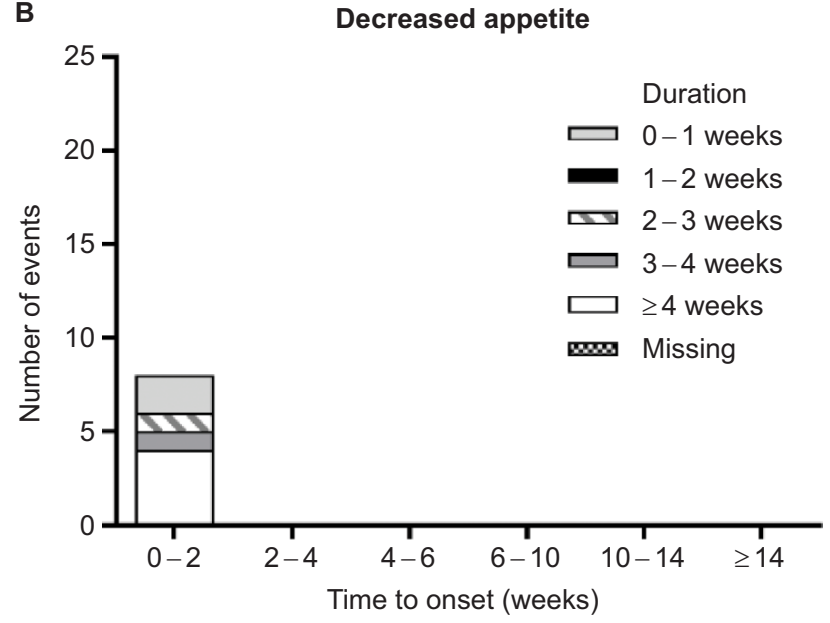

D

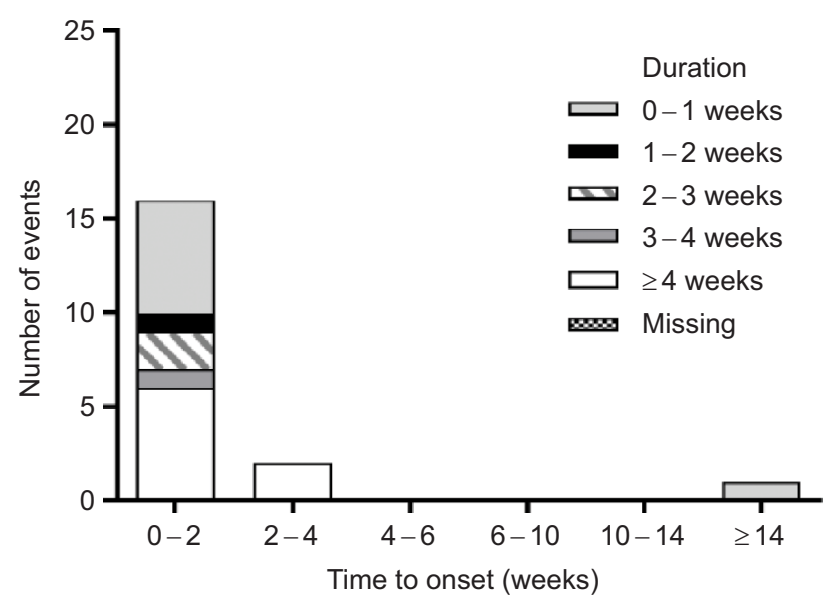

F

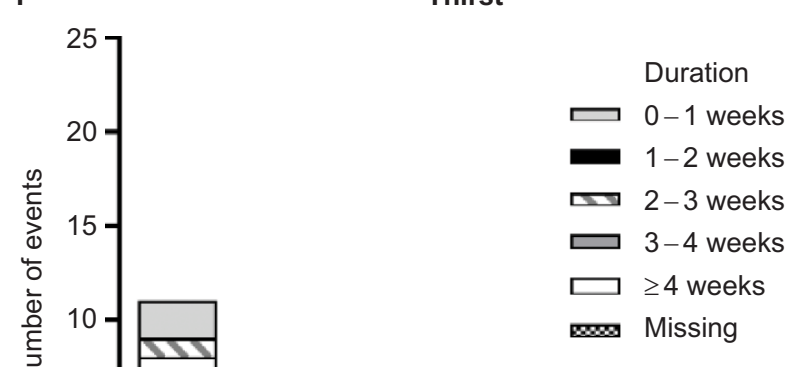

Figure S2 TR-AESls by time to onset and duration in patients treated with duloxetine for 14 weeks.

Note: TR-AESls included constipation (A), decreased appetite (B), malaise (C), nausea (D), somnolence (E), and thirst (F).

Abbreviation: TR-AESIs, treatment-related adverse events of special interest. 
A $\quad \geq 30 \%$ pain reduction

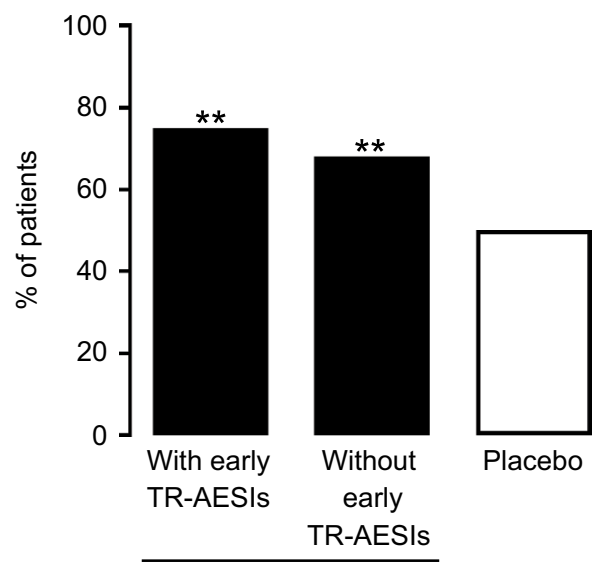

Duloxetine $60 \mathrm{mg} / \mathrm{day}$

B

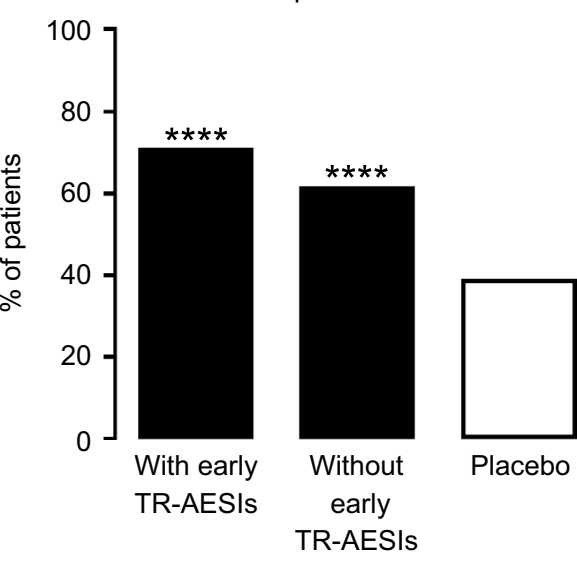

Duloxetine $60 \mathrm{mg} / \mathrm{day}$

Figure S3 Proportion of patients who achieved $\geq 30 \%$ (A) or $\geq 50 \%$ (B) pain reduction after 14 weeks of treatment with placebo or duloxetine.

Notes: Duloxetine subgroups are patients with or without treatment-related adverse events of special interest between baseline and Week 2. $* * P<0.01$, $* * * * P \leq 0.000$ I compared with placebo.

Abbreviation: TR-AESIs, treatment-related adverse events of special interest.

\section{Publish your work in this journal}

The Journal of Pain Research is an international, peer reviewed, open access, online journal that welcomes laboratory and clinical findings in the fields of pain research and the prevention and management of pain. Original research, reviews, symposium reports, hypothesis formation and commentaries are all considered for publication.

\section{Dovepress}

The manuscript management system is completely online and includes a very quick and fair peer-review system, which is all easy to use. Visit http://www.dovepress.com/testimonials.php to read real quotes from published authors. 